Jonathan Marshall

\title{
Jesus, Patrons, and Benefactors
}

\author{
Roman Palestine and the Gospel of Luke
}

[Jesus, Patrone und Wohltäter. Palästina unter römischer Herrschaft und das Lukasevangelium.]

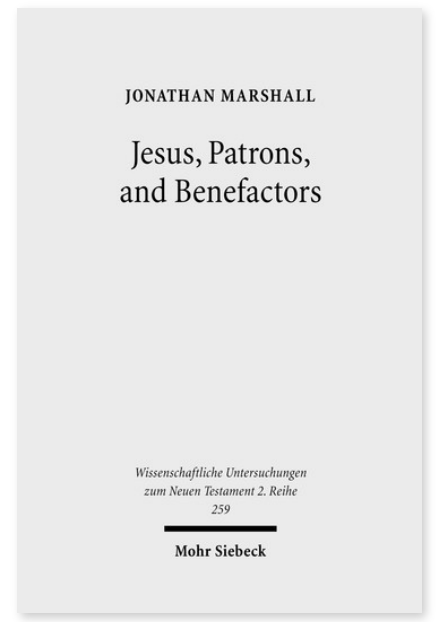

2009. XIII, 383 Seiten. WUNT II 259

ISBN 978-3-16-151602-3

DOI 10.1628/978-3-16-151602-3

eBook PDF 94,00€

ISBN 978-3-16-149901-2

fadengeheftete Broschur 94,00€
Veröffentlicht auf Englisch.

Hat Jesus das römische Patrozinium direkt angegriffen und sich selbst als Wohltäter schlechthin dargestellt? Studien über den historischen Jesus beziehen sich oft auf solche Klassifizierungen in ihren Beschreibungen von Jesus und den Evangelien. Anhand historischer Nachforschungen untersucht Jonathan Marshall diese Deutungen kritisch. Zunächst gibt er einen Überblick über bedeutende archäologische und historische Zeugnisse, die für das Palästina des 1. Jahrhunderts relevant sind. Danach untersucht er die Darstellung Jesu durch Lukas in drei exemplarische Passagen (6,17-38; 14,1-24; 22,14-34). Lukas' Vernachlässigung des Patroziniums und sein eingeschränkter Gebrauch des Begriffs 'Wohltat' bei der Beschreibung von Jesus stimmt mit den Realia Palästinas, die durch grundlegende Quellen gestützt werden, überein.

Jonathan Marshall Born 1978; 2008 PhD; taught courses at Biola University (La Mirada, CA) and Eternity Bible College (Simi Valley, CA); currently Associate Pastor in the Camarillo Evangelical Free Church (EFCA; Camarillo, CA).

\section{Jetzt bestellen:}

https://mohrsiebeck.com/buch/jesus-patrons-and-benefactors-9783161516023?no_cache=1 order@mohrsiebeck.com

Telefon: +49 (0)7071-923-17

Telefax: $+49(0) 7071-51104$ 